\title{
Nanophotonics
}

SPIEDigitalLibrary.org/jnp

\section{Commentary: Luster ceramics: a 9th century AD nanotechnology}

Aurelio Climent-Font 


\title{
Commentary: Luster ceramics: a 9th century AD nanotechnology
}

\author{
Aurelio Climent-Font \\ University Autonoma Madrid, Department of Applied Physics and CMAM, Cantoblanco, \\ 28049 Madrid, Spain \\ acf@uam.es
}

Paper 12117CT received Aug. 22, 2012; revised manuscript received Aug. 28, 2012; accepted for publication Aug. 30, 2012; published online Oct. 19, 2012.

Photonic crystals are composed of periodic metallo-dielectric nanostructures that affect the propagation of light. The concept was proposed by Yablonovitch 25 years ago ${ }^{1}$ and today is an active, ongoing field of research with high prospects for potential applications in the field of photonics. It is known that nature has provided such nanostructures in minerals and living creatures. Sparkling opals, consisting of submicron size silica spheres arranged in a face-centered cubic structure, the iridescent tail feathers of the peacock, or the Morpho butterfly's blue shining color wings consisting of regular rows of thin plates so-called scales, are examples. We can refer to the brilliancy of these colors resulting from reflection and diffraction in the nano-structured material as structural colors, in contrast to pigmentary colors that result from absorption of light by pigments. ${ }^{2}$ Yet, in the early Middle Ages, in the 9th century AD, Islamic potters in Iraq succeeded in decorating glazed ceramics with vivid colors showing iridescent effects, very much like structural colors. These have been revealed to be caused by metallic nanoparticles buried below the glaze surface that the ancient potters were able to diffuse through empirical, carefully controlled heat treatments.

\section{History of the Luster Technique}

Luster ceramic is the name given to the decorated ceramic first achieved by the Islamic ceramists in Mesopotamia in cities like Samarra and Basra, present-day Iraq, during the 9th century $\mathrm{AD}$ under the Abbasid dynasty. The polychrome luster had diverse colors showing metallic shine, including yellowish colors like gold. ${ }^{3,4}$ Although the mastering of the technique was a professional secret, the know-how of the decorative technique spread to neighboring areas, probably due to social and political instabilities forcing master-potters to migrate from one city to another. So, luster ceramics were found in Fustat, the pre-Cairo capital of Egypt, during the Fatimid dynasty (9th to 12th centuries), Syria (12th to 15th centuries), Iran (12th to 17th centuries), having in each period and place its characteristic style. ${ }^{4}$

Following the Islamic expansion along the Mediterranean coast of North Africa, up to the Iberian Peninsula, the luster technique was established in the south of Spain, in al-Andalus (10th to 15th centuries), notably in the cities of Malaga and Valencia, where the best production flourished under the Nasrid dynasty (13th to 15th centuries). After the Christian conquest of the region of Valencia in the 13th century, the luster technique was learned by Christian potters. During the 14th and 15th centuries the luster production technique of the local sites of Paterna and Manises, near Valencia, became very well known and appreciated in the eastern part of the Islamic empire as well as in the European aristocratic courts of Italy, France, and the Netherlands. The production of this period is known as Hispano-Moresque.

In the second half of the 15th century, the Spanish potters transmitted the know-how of the technique to the Italians of the Renaissance period, where cities like Gubbio, Deruta, and Cafaggiolo, in the present-day region of Umbria, started producing luster artifacts mixed with their own local chromatic technology with pigments. This production of artifacts is known as lustered majolica. ${ }^{4}$

0091-3286/2012/\$25.00 (C) 2012 SPIE 


\section{Unraveling the Technology of Luster}

The oldest known recipe describing luster technique is the Abul'l-Qasim's treatise of 1301. The essential point of the technique is that once the ceramic glaze, formed heating at temperatures around $1000^{\circ} \mathrm{C}$, has cooled down, a paste containing molten clay minerals, iron oxides, sulfur (cinnabar), silver and/or copper compounds, all diluted with strong vinegar, is applied on the glaze, defining the decorative motifs. The object with the decorating paste is then subjected to a mild heat treatment of $500^{\circ} \mathrm{C}$ to $600^{\circ} \mathrm{C}$, changing the ambient from oxidizing to reducing. After several hours of heat treatment, the remains of the applied paste are cleaned with water, and if the process has been successful, a luster ceramic object, is obtained. Figure 1, shows in two images the metallic reflection effect of a shard of golden luster ceramics produced in the Catalonian region of Spain in the 18th century, Fig. 1(a) shows a view with non-reflecting light, and Fig. 1(b) shows it slightly tilted giving a light reflecting view.

The complexity of the process, including temperature, time, ambiance, composition of the decorating paste, and even composition of the previously formed glaze, did not guarantee that every trial would result in a successful object. It is really intriguing how the potters were able to find empirically such a process to decorate the glazed ceramic, although procedures to color glass, that we now know are due to the presence of metallic nanoparticles dissolved in the glass, have existed since very old times and were known to the Egyptians and Romans. ${ }^{5}$ Figure 2 shows graphically the process of the formation of nanoparticles producing the luster. Experimental evidence of the presence of a layer of nanoparticles in the colored region was obtained by transmission electron microscopy (TEM). ${ }^{6}$ Ionic interchange of $\mathrm{Ag}$ and/or $\mathrm{Cu}$ ions diffusing in the glaze from the decorating paste with alkali ions, $\mathrm{Na}$ and $\mathrm{K}$, out diffusing from the glaze would be of crucial importance for the posterior nucleation of metallic nanoparticles. ${ }^{7}$ The nature of the nanoparticles, normally $\mathrm{Ag}$ and/or $\mathrm{Cu}$, as well as their shape and size and the distance among them will affect the color and the reflectivity of the luster. The optical properties of luster have been successfully modeled considering its structure of a buried layer of nanoparticles and taking into account physical phenomena such as surface plasmon absorption, interference, and scattering. ${ }^{8}$ Information on the oxidation state of $\mathrm{Ag}$ and $\mathrm{Cu}$ elements in the luster has been obtained using extended X-ray absorption fine structure, ${ }^{9}$ and quantitative determination of the concentration of $\mathrm{Ag}$ and $\mathrm{Cu}$ in the luster layer, as well as its depth composition profile, have been determined through elastic ion backscattering (EIBS). ${ }^{10}$ A combination of TEM and EIBS experiments has allowed us to determine in the case of modern laboratory made $\mathrm{Cu}$ lusters the mean ratio interparticle distance/size producing metallic reflection. ${ }^{11}$

The physical structure underlying luster technology and the fundamentals of the optical effects of the decoration seem now well understood. ${ }^{12}$ Some doubts exist, though, on the mechanisms causing the diffusion of the metallic elements from the applied paste to the interior of the glaze. Is it the ion exchange mechanism plus the mild temperature heat treatment enough for the diffusion to occur, or as it has been suggested, ${ }^{13}$ an extra source of heat like local combustion of organic residues is needed? Another open question is related to the composition of the
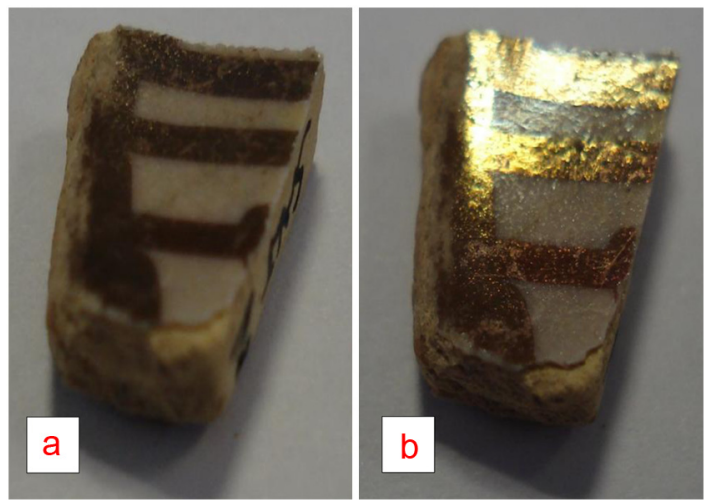

Fig. 1 The metallic reflection effect is shown in two views of a shard of golden luster ceramics produced in the Catalonian region of Spain in the XVIII century. (a) View out of the reflecting angle of incident light. (b) View in the reflecting angle of incident light. 


\section{The luster process}

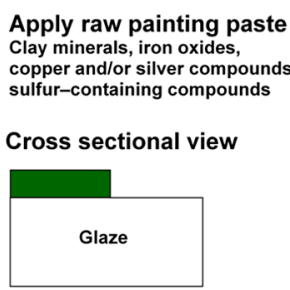

Top view

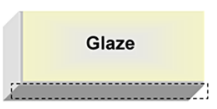

Initial view before applying the paste

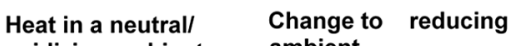
$600^{\circ} \mathrm{C}$

lon exchange process

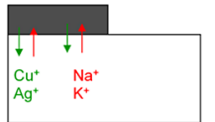

ambient

Continue heat treatment

allowing the growth of metallic nanoparticles
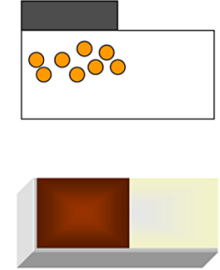

Final view after removing the residual paste

Parameters of interest in the luster nanostructure

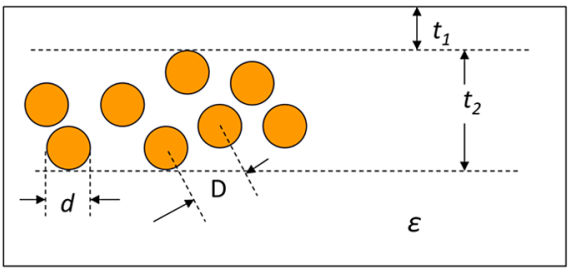

$t_{1}$ : thickness of the surface glaze several tens $\mathrm{nm}$ $t_{2}$ : thickness of the luster layer several hundreds $\mathrm{nm}$ d: 5 to $50 \mathrm{~nm}$ (Mie scattering)

D: $D / d 1.14-1.7$

Among all metals, $\mathrm{Cu}, \mathrm{Ag}$ and $\mathrm{Au}$ and alkali metals have the surface plasmon absorption peak in the visible wave length range.

Typical colors in the $9^{\text {th }}$ century Abbasid lusters are: olive green, brown, amber (Ag rich) yellow, orange, crimson, and dark red (Cu rich)

Sometimes the artifacts show metallic shine.

Fig. 2 Schematic description of the process of formation of metallic nanoparticles inside the glaze, constituting the luster decoration, according to the ionic exchange mechanism of Ref. 7 .

glaze and the associated diffusivity of the metal species. The point would be if the amount of lead oxide in the glaze affects the diffusivity of the $\mathrm{Ag}$ and $\mathrm{Cu}$ species. In order for the luster layer to produce the metallic reflection effect, a minimum concentration of nanoparticles is required, and the necessary gradient of concentration will be dependent on the diffusivity, which in turn will be affected by the temperature and time of the heat treatment. In principle, these questions should not be difficult to answer with appropriate experiments.

\section{References}

1. E. Yablonovitch, "Inhibited spontaneous emission in solid-state physics and electronics," Phys. Rev. Lett. 58(20), 2059-2062 (1987), http://dx.doi.org/10.1103/PhysRevLett.58 2059.

2. S. Kinoshita, S. Yoshioka, and J. Miyazaki, "Physics of structural colors," Rep. Prog. Phys. 71(7), 076401 (2008), http://dx.doi.org/10.1088/0034-4885/71/7/076401.

3. R. B. Mason, "Shine like the sun. Lustre-painted and associated pottery from the medieval Middle East," In Bibliotheca Iranica: Islamic Art and Architecture Series, Vol. 12, Mazda Publishers Inc., Costa Mesa (2004).

4. A. Caiger-Smith, "Luster Pottery: Technique, Tradition and Innovation in Islam and the Western World,” Faber and Faber, London (1985), ISBN 0.571-13507-2. 
5. I. Angelini et al., "Chemical analysis of Bronze age glasses from Frattesina do Rovigo, Northern Italy," J. Archaeolog. Sci. 31(8), 1175-1184 (2004), http://dx.doi.org/10.1016/j .jas.2004.02.015.

6. J. Pérez-Arantegui et al., "Luster pottery from the thirteenth century to the sixteenth century: a nanostructured thin metallic film," J. Am. Ceram. Soc. 84(2), 442-446 (2001), http://dx .doi.org/10.1111/j.1151-2916.2001.tb00674.x.

7. T. Pradell et al., "Ionic-exchange mechanism in the formation of medieval luster decorations," J. Am. Ceram. Soc. 88(5), 1281-1289 (2005), http://dx.doi.org/10.1111/jace.2005 88.issue-5.

8. V. Reillon, S. Berthier, and C. Andraud, "Optical properties of lustred ceramics:complete modeling of the actual structure," Appl. Phys. A 100(3), 901-910 (2010), http://dx.doi.org/ 10.1007/s00339-010-5791-0.

9. A. D. Smith et al., "Color variations in 13th century hispaic luster-an EXAFS study," J. Non-Crystalline Solids 352(50-51), 5353-5361 (2006), http://dx.doi.org/10.1016/j .jnoncrysol.2006.08.024.

10. G. Padeletti et al., "First-time observation of maestro Giorgio masterpieces by means of non-destructive techniques," Appl. Phys. A 83(4), 475-483 (2006), http://dx.doi.org/10 .1007/s00339-006-3549-5.

11. T. Pradell et al., "Metallic and non metallic shine in luster: an elastic ion backscattering study," J. Appl. Phys. 101(10), 103518 (2007), http://dx.doi.org/10.1063/1.2734944.

12. P. Sciau, "Nanoparticles in ancient materials: the metallic lustre decoration of medieval ceramics," Chapter 25 in The Delivery of Nanoparticles, Abbass A. Hashim, Ed., InTech (2012), http://dx.doi.org/10.5772/34080.

13. C. Mirguet et al., "Origin of self-organization of $\mathrm{Cu}^{\circ} / \mathrm{Ag}^{\circ}$ nanoparticles in ancient lustre pottery. A TEM study," Phase Transitions 81(2-3), 253-266 (2008), http://dx.doi.org/10 $.1080 / 01411590701514433$. 